\title{
Fenofibrate decreases radiation sensitivity via peroxisome proliferator-activated receptor $\alpha$-mediated superoxide dismutase induction in HeLa cells
}

\author{
Xianguang Liu, MD'1, Seong Soon Jang, MD, PhD², Zhengzhe An, MS¹, Hyejin Song, MS', \\ Won-Dong Kim, MD, PhD' ${ }^{1}$, Jae-Ran Yu, MD, PhD³ , Woo-Yoon Park, MD, PhD ${ }^{1}$ \\ Department of Radiation Oncology, ${ }^{1}$ Chungbuk National University College of Medicine, Cheongju; \\ ${ }^{2}$ The Catholic University of Korea College of Medicine, Seoul; \\ ${ }^{3}$ Department of Environmental and Tropical Medicine, Konkuk University College of Medicine, Chungju, Korea
}

Purpose: The fibrates are ligands for peroxisome proliferator-activated receptor (PPAR) $\alpha$ and used clinically as hypolipidemic drugs. The fibrates are known to cause peroxisome proliferation, enhance superoxide dismutase (SOD) expression and catalase activity. The antioxidant actions of the fibrates may modify radiation sensitivity. Here, we investigated the change of the radiation sensitivity in two cervix cancer cell lines in combination with fenofibrate (FF).

Materials and Methods: Activity and protein expression of SOD were measured according to the concentration of FF. The mRNA expressions were measured by using real time reverse-transcription polymerase chain reaction. Combined cytotoxic effect of FF and radiation was measured by using clonogenic assay.

Results: In HeLa cells total SOD activity was increased with increasing FF doses up to $30 \mu \mathrm{M}$. In the other hand, the catalase activity was increased a little. As with activity the protein expression of SOD1 and SOD2 was increased with increasing doses of FF. The mRNAs of SOD1, SOD2, PPAR $\alpha$ and PPAR $\gamma$ were increased with increasing doses of FF. The reactive oxygen species (ROS) produced by radiation was decreased by preincubation with FF. The surviving fractions (SF) by combining FF and radiation was higher than those of radiation alone. In Me180 cells SOD and catalase activity were not increased with FF. Also, the mRNAs of SOD1, SOD2, and PPAR $\alpha$ were not increased with FF. However, the mRNA of PPAR $\gamma$ was increased with FF.

Conclusion: FF can reduce radiation sensitivity by ROS scavenging via SOD induction in HeLa. SOD induction by FF is related with PPAR $\alpha$.

Keywords: Fenofibrate, Radiation sensitivity, Peroxisome proliferator-activated receptor $\alpha$, Superoxide dismutase

\section{Introduction}

The fibrates are ligands for peroxisome proliferator-activated receptor $\alpha$ (PPAR $\alpha)$ and some of them are used clinically as hypolipidemic drugs to reduce blood triglyceride and cholesterol [1-4]. All PPARs belong to the nuclear hormonal receptor superfamily and forms a heterodimer with retinoid $X$ receptor (RXR), another nuclear hormonal receptor [5].

Received 20 October 2011, Revised 3 April 2012, Accepted 13 June 2012.

Correspondence: Woo-Yoon Park, MD, PhD, Department of Radiation Oncology, Chungbuk National University College of Medicine, 52 Naesudong-ro, Heungdeok-gu, Cheongju 361-804, Korea. Tel: +82-43-269-6218, Fax: +82-43-269-6208, E-mail: wynpark@chungbuk.ac.kr

(c) This is an Open Access article distributed under the terms of the Creative Commons Attribution Non-Commercial License (http://creativecommons.org/ licenses/by-nc/3.0/) which permits unrestricted non-commercial use, distribution, and reproduction in any medium, provided the original work is properly cited. www.e-roj.org 
The dimers interact with peroxisome proliferator response element (PPRE) and activate transcription of the target genes [6]. PPARs contain the functional domains including DNA binding domain (DBD) and ligand binding domain (LBD). PPAR/ RXR heterodimers bind to a PPRE located in the promoter of target genes through the DBD. Natural and synthetic ligands bind to the $L B D$, either activating or repressing the receptor [5]. So far, three isoforms of PPAR, i.e., $\alpha, \beta / \delta$, and $\gamma$, have been reported [7]. Although PPARs share extensive structural homology, each isoform differs in their cell and tissue distribution as well as in their target genes. PPAR $\alpha$ is distributed mainly in the metabolically active tissues, like liver, kidney and heart. The major action of PPAR $\alpha$ is the regulation of fatty acid metabolism [8,9]. Another action of PPAR $\alpha$ is the upregulation of peroxisomes. The fibrates and 4-chloro-6(2,3-xylidine)-2-pyrimidinylthioacetic acid (Wy-14643), one of PPAR $\alpha$ ligands, are known to cause peroxisome proliferation and hepatomegaly in rodents [6]. Recently PPAR $\alpha$ has been demonstrated to be an activator of anti-oxidative enzymes, such as catalase and superoxide dismutase (SOD) and antiinflammatory mediators [10-17].

Radiation effects may occur as direct ionizations in an organic molecule or indirectly via free radical processes. In the indirect action, which is dominant in treatment with $x$-rays and $\gamma$-rays commonly used in clinical radiotherapy, radiation interacts with cellular molecules (mainly water) to produce free radicals, such as hydroxyl radicals $\left({ }^{\circ} \mathrm{OH}\right)$ and aqueous electrons $\left(\mathrm{e}_{\text {aq }}^{-}\right)$. The radiation-induced reactive oxygen species (ROS) will undergo further reactions. The aqueous electron reacts with oxygen to produce the superoxide anion radicals $\left(\mathrm{O}_{2}{ }^{--}\right)$. The spontaneous or SOD-catalyzed dismutation of superoxide generates hydrogen peroxide $\left(\mathrm{H}_{2} \mathrm{O}_{2}\right)$, which yields the highly toxic hydroxyl radicals through a Fenton reaction or a Haber-Weiss reaction [18]. Most of the x-ray and $\gamma$-ray damage is caused by free radicals which not only kill tumor cells by inducing mitotic failure or apoptotic death, but also give harm to the surrounding normal cells.

The antioxidant actions of the fibrates may modify radiation sensitivity. If the patients taking the fibrates undergo radiation therapy the results may be changed. However, there is no report on this issue. Here, we investigated the change of the radiation sensitivity in cervix cancer cells combined with fenofibrate (FF), which is commonly used to reduce triglyceride.

\section{Materials and Methods}

\section{Cells and culture conditions}

The two cervix cancer cell lines (HeLa, Me180) were purchased from the Korean Cell Line Bank (Seoul, Korea). The cells were grown in Dulbecco's modified Eagle's medium (DMEM) containing 10\% fetal bovine serum supplemented with $100 \mathrm{IU} /$ $\mathrm{mL}$ penicillin, $100 \mu \mathrm{g} / \mathrm{mL}$ streptomycin. The cells were kept in a humidified atmosphere containing $5 \% \mathrm{CO}_{2}$ at $37^{\circ} \mathrm{C}$. FF was purchased from Sigma-Aldrich Co. (St. Louis, MO, USA) and dissolved in dimethyl sulfoxide (DMSO) at a final concentration of less than 0.1\% DMSO in the culture medium. All standard culture reagents were from Invitrogen (Carlsbad, CA, USA).

\section{Protein extraction for Western blot and catalase acti- vity assay}

Cell proteins was obtained by rinsing the cells with phosphatebuffered saline (PBS) pH 7.2 three times, scraping the cells from the culture flasks with a rubber policeman, and centrifuging at 1,000 rpm for 10 minutes. The cells were washed with PBS two times and pellets were kept frozen at $-80^{\circ} \mathrm{C}$ until used. At the time of analysis, the cell pellets were resuspended in one volume of $50 \mathrm{mM}$ potassium phosphate buffer ( $\mathrm{pH}$ 7.85) and sonicated on ice 3 times for 10 seconds using a Vibra cell sonicator (Branson 1510R-DTH; Branson, Danbury, CT, USA). Protein concentration was determined using the Bradford method using bovine serum albumin as a standard [19].

\section{Superoxide dismutase activity assay}

Superoxide dismutase activity was assayed using an assay kit (Dojindo, Gaithersburg, MD, USA). Briefly, $1 \times 10^{4}$ cells were seeded in each well of 96-well micoplates and next day, treated with various concentration of FF for 48 hours. After adding a set of assay solutions as indicated in the manufacturer's protocol the absorbance at $450 \mathrm{~nm}$ was measured using a microplate reader and SOD activity were calculated.

\section{Catalase activity assay}

Catalase activity was quantitated spectrophotometrically following the decomposition of $\mathrm{H}_{2} \mathrm{O}_{2}$ at $240 \mathrm{~nm}$ [20].

\section{Western blot analysis}

Proteins was denatured in 1 volume of sample buffer containing $62.5 \mathrm{mM}$ Tris- $\mathrm{HCl}$ (pH 6.8), 10\% glycerol, 2\% sodium dodecyl sulfate (SDS), 5\% $\beta$-mercaptoethanol (v/v) and 2-3 
drops of saturated bromophenol blue solution at $100^{\circ} \mathrm{C}$ for $3 \mathrm{~min}$. The proteins were separated in a 12.5\% denaturing polyacrylamide gel by electrophoresis and then transferred onto nitrocellulose membranes at $100 \mathrm{~V}$ for 1 hour at $4^{\circ} \mathrm{C}$ The blots were then blocked in 4\% dry milk in TTBS (0.02 M Tris buffer [pH 7.0] and 0.5\% Tween 20) at room temperature for 2 hours and incubated with primary antibody $(1: 1,000)$ in TTBS at $4^{\circ} \mathrm{C}$ overnight. After washing three times with TTBS, 5 minutes each, the blots were incubated with secondary antibody $(1: 10,000)$. After washing three times, the blots were visualized using chemiluminescence. The antibodies for CuZnSOD (SOD1), MnSOD (SOD2) and catalase were purchased from AbFrontier (Seoul, Korea).

\section{RNA isolation and quantitative real-time polymerase chain reaction}

RNA was isolated from the cells using TRIzol reagent according to the manufacturer's protocol (Invitrogen). cDNA was synthesized using iScript reverse transcriptase reagent (BioRad, Hercules, CA, USA) from $1 \mu \mathrm{g}$ of RNA. The following primers were used for the real-time quantitative reversetranscription polymerase chain reaction ( $R T-P C R$ ) with SOD1 (forward, 5'-CTCTCAGGAGACCATTGCATCAT-3'; reverse, 5'-CCAATTACACCACAAGCCAAACG-3'), SOD2 (forward 5'-TCAATAAGGAACGGGGACAC-3'; reverse 5' GTA GTAAGCGTGCTCCCACAC-3'), and PPAR $\alpha$ (forward 5'-GGCGAATATGCTCAATGGT-3'; reverse 5'-GGCCACGAATTTTGAGGTTA-3'). The RT-PCR was performed with $20 \mu \mathrm{L}$ of reaction solution containing diluted cDNA, 20 pmol of each primer, and $10 \mu \mathrm{L}$ of two-step SYBR Green PCR Master Mix (Invitrogen). The thermal cycling parameters were $95^{\circ} \mathrm{C}$ for 10 minutes for Taq polymerase activation followed by 40 cycles of $95^{\circ} \mathrm{C}$ for 15 seconds and $60^{\circ} \mathrm{C}$ for 1 minute. The reactions were performed in triplicate in each experiment. The threshold number of cycles $\left(C_{t}\right)$ was recorded from each sample for both the target gene and the reference gene (GAPDH). Melting curve analysis was performed for each run. The relative expression of the target gene was calculated as $\Delta \Delta C_{t}$ determined by subtracting $\Delta C_{t}$ of the reference gene from $\Delta C_{t}$ of the target gene. Each experiment was performed independently three times.

\section{ROS measurement}

Intracellular production of ROS was measured using the fluorescent dye, 2',7'-dichlorodihydrofluorescein-diacetate ( $\mathrm{H}_{2}$ DCFDA; Sigma, St. Louis, MO, USA) as described by Wan et al. [21]. Two days prior to experiments, cells were plated on 60 $\mathrm{mm}$ dishes. After drug treatment the cells were rinsed with PBS (no phenol red, $\mathrm{Ca} 2+$, or $\mathrm{Mg} 2+$ ) and incubated with $10 \mu \mathrm{M}$ of $\mathrm{H} 2 \mathrm{DCFDA}$ at $37^{\circ} \mathrm{C}$ for 10 minutes, and then irradiated using a linear accelerator (Mevatron; Siemens, Concord, CA, USA) at room temperature. The cells were detached with $0.25 \%$ trypsin and $0.11 \%$ ethylenediaminetetraacetic acid (EDTA), washed and resuspended in cold PBS and placed on ice, and analyzed using a FACScan flow cytometer (FACS Calibur-S; 488 nm excitation, 530 nm emission; Becton Dickinson, San Jose, CA). The mean geometric fluorescence intensity for 30,000 cells was analyzed for each sample using CellQuest Pro (BD Biosciences, San Jose, CA, USA).

\section{Clonogenic assay}

After treated with FF for defined duration the cells were irradiated. Irradiation was done using a linear accelerator (Mevatron; Siemens) with a dose rate of $3 \mathrm{~Gy} / \mathrm{min}$ at room temperature. The cells were trypsinized and varying number of cells for optimal colony counting was seeded in $60 \mathrm{~mm}$ dishes. After 6-7 days the cells were stained with $0.1 \%$ crystal violet solution and the number of colonies, composed of at least 50 cells, was counted. Surviving fraction (SF) was calculated as follows: SF = plating efficiency (PE) of treated cells / PE of control cells. PE (\%) was obtained from (colonies counted / cells plated) $\times 100$. Cell survival curves were plotted by using linear regression model.

\section{Results}

\section{Effect of FF on total SOD and catalase activity}

Total SOD and catalase activity was measured in the cells treated with $0,3,10,30,60 \mu \mathrm{M}$ of FF for 48 hours. Total SOD activity was increased with increasing FF doses and it was maximal at $30 \mu \mathrm{M}$ of FF: about two times higher than control in HeLa cells (Fig. 1). However, SOD activity was not increased with FF treatment in Me180 cells (Fig. 1). The catalase activity was increased about $40 \%$ at $3 \mu \mathrm{M}$ of FF in HeLa cells, but it was not increased at all dose ranges tested in Me180 cells (Fig. 1).

\section{Effect of FF on SODs and catalase protein induction}

To investigate whether the SOD and catalase activity is related with their protein expression, Western blot was done for SOD1, SOD2 and catalase in HeLa cells treated with various doses of FF for 48 hours. As with the activity the protein expression of SOD1 and SOD2 were increased with increasing doses of FF (up 

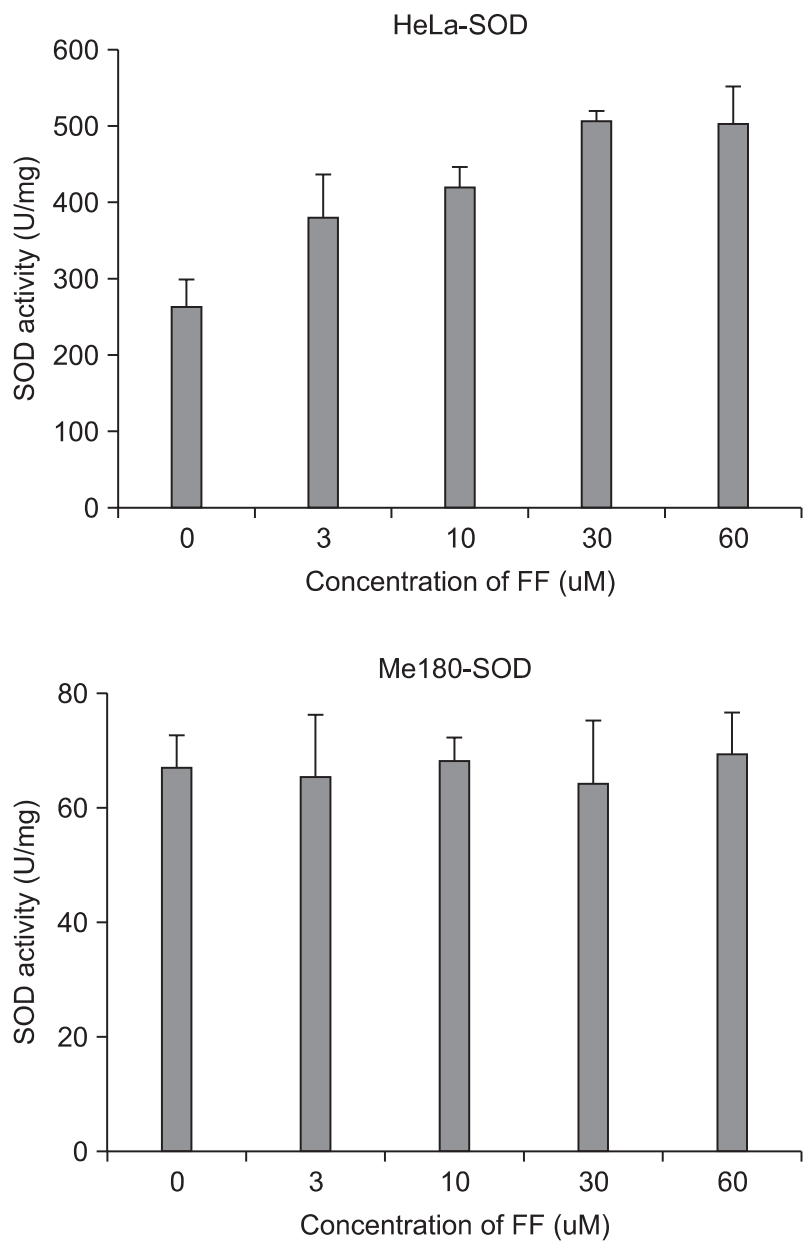

Fenofibrate decreases radiation sensitivity via SOD induction
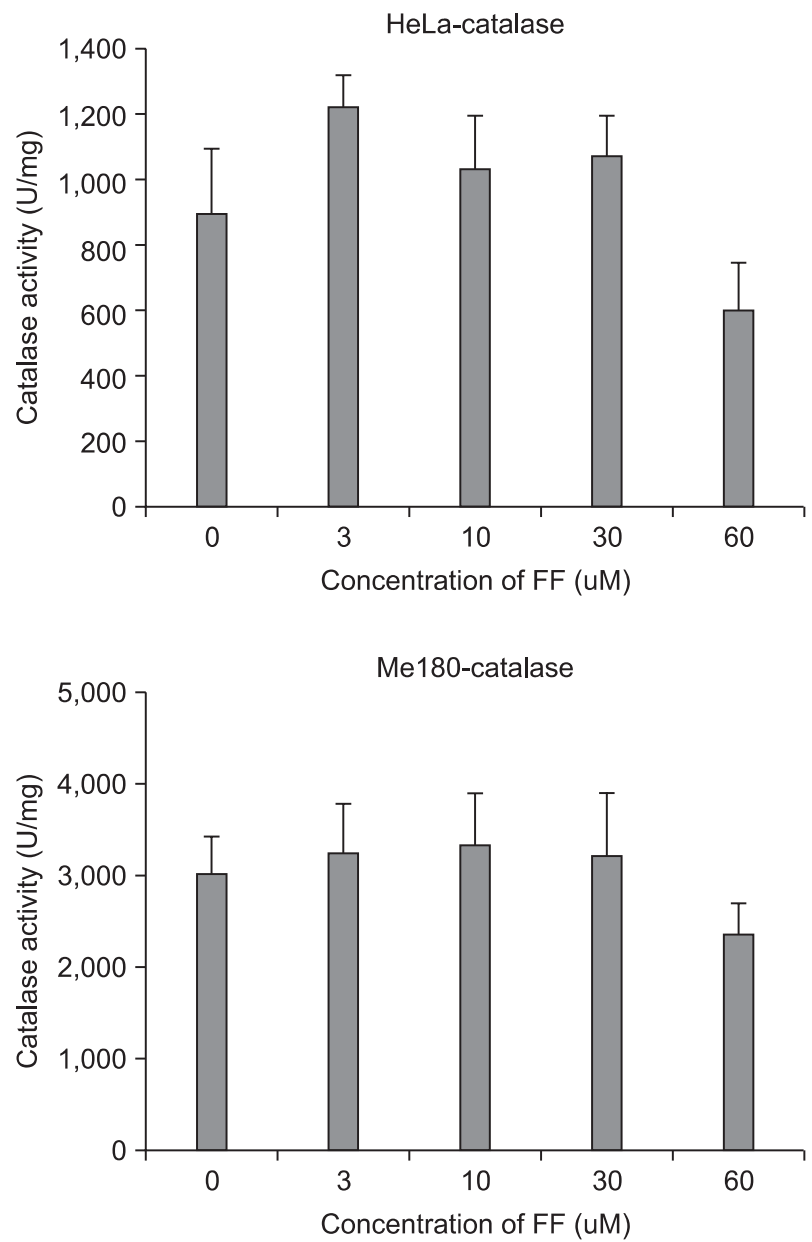

Fig. 1. Effect of fenofibrate (FF) on total superoxide dismutase (SOD) and catalase activity in HeLa and Me180 cells. Cells were treated with the indicated concentrations of FF for 48 hours. Dose-dependent effect of FF treatment on total SOD and catalase activity determined by SOD and catalase activity assay.

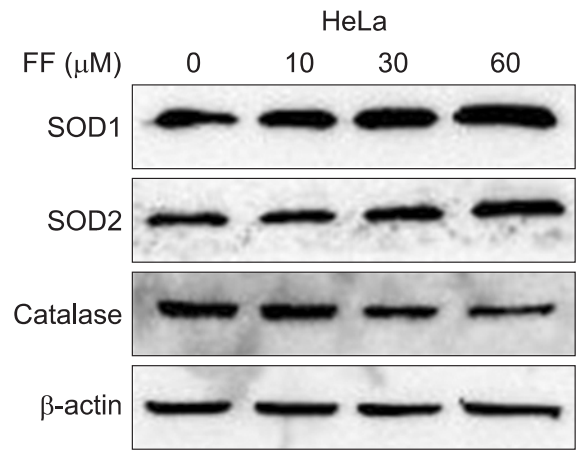

Fig. 2. Effect of fenofibrate (FF) on superoxide dismutases (SODs) and catalase protein expression in HeLa cells. Cells were treated with 0-60 $\mu \mathrm{M}$ concentration of FF for 48 hours. Equal amounts of lysates were subjected to electrophoresis and analyzed by Western blotting for SOD1, SOD2 and catalase as described under Materials and Methods. to $60 \mu \mathrm{M})$ and that of catalase was decreased with increasing doses (30 and $60 \mu \mathrm{M}$ ) of FF (Fig. 2).

\section{Effect of FF on SOD mRNA expression}

To investigate whether protein expression of SOD1 and SOD2 is related with their mRNA expression, cells were treated with varying doses of FF for 48 hours and real time RT-PCR was done. Both mRNA of SOD1 and SOD2 were increased with increasing doses of FF in HeLa cells, but they were not increased in Me180 cells (Fig. 3). This suggests increased protein expression of SOD1 and SOD2 by FF are caused from increased expression of their mRNA.

\section{Effect of FF on PPAR $\alpha$ and PPAR $\gamma$ mRNA expression}

To investigate whether protein expression of SOD1 and SOD2 is related with PPAR $\alpha$ and PPAR $\gamma$ mRNA expression, cells were treated with varying doses of FF for 48 hours and real time RT- 

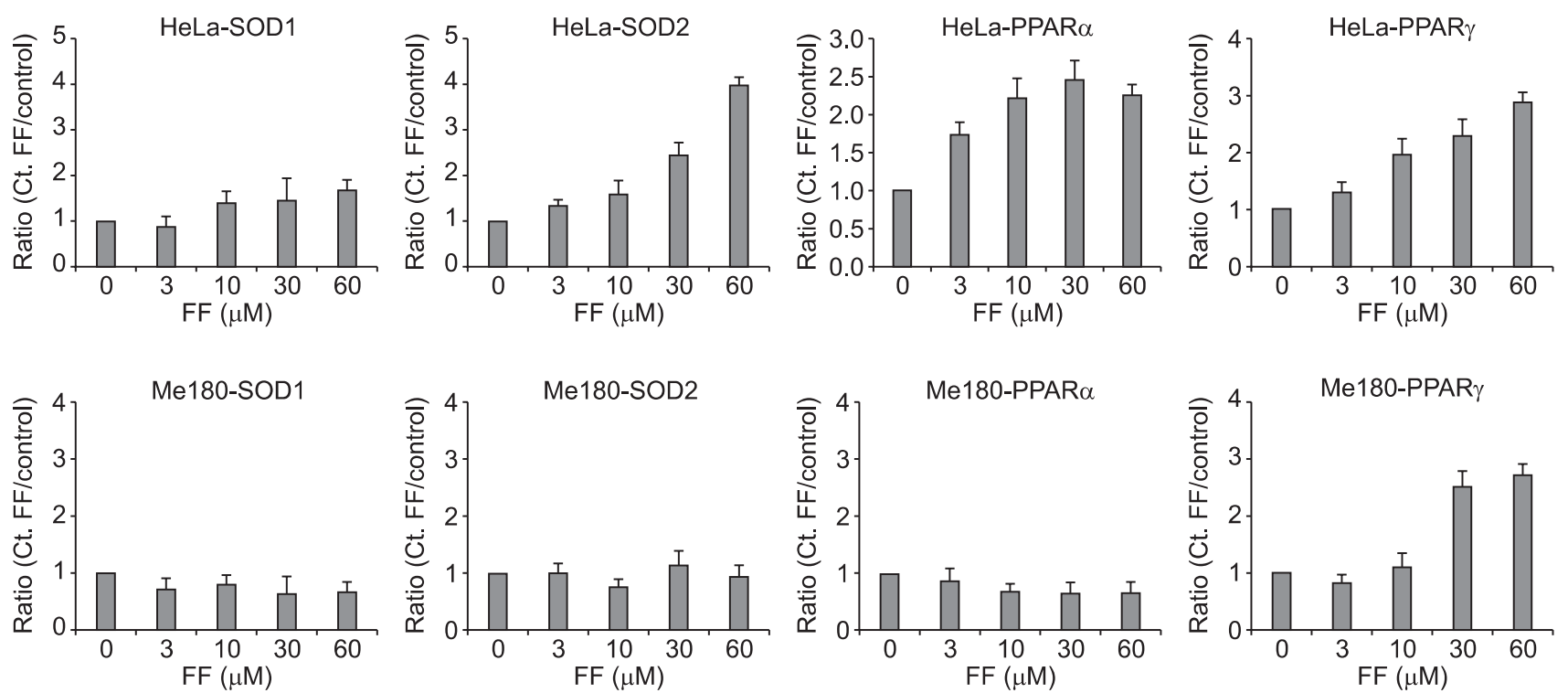

Fig. 3. Effect of fenofibrate (FF) on the mRNA expression of superoxide dismutase 1 (SOD1), SOD2, peroxisome proliferator-activated receptor $\alpha$ (PPAR $\alpha)$, and PPAR $\gamma$ in HeLa and Me180 cells. Cells were treated with the indicated concentrations of FF for 48 hours and RNA was isolated for reverse-transcription polymerase chain reaction analysis of PPAR $\alpha$ gene expression as explained in Material and Methods. Data are presented as fold changes compared to sham-treated cells.
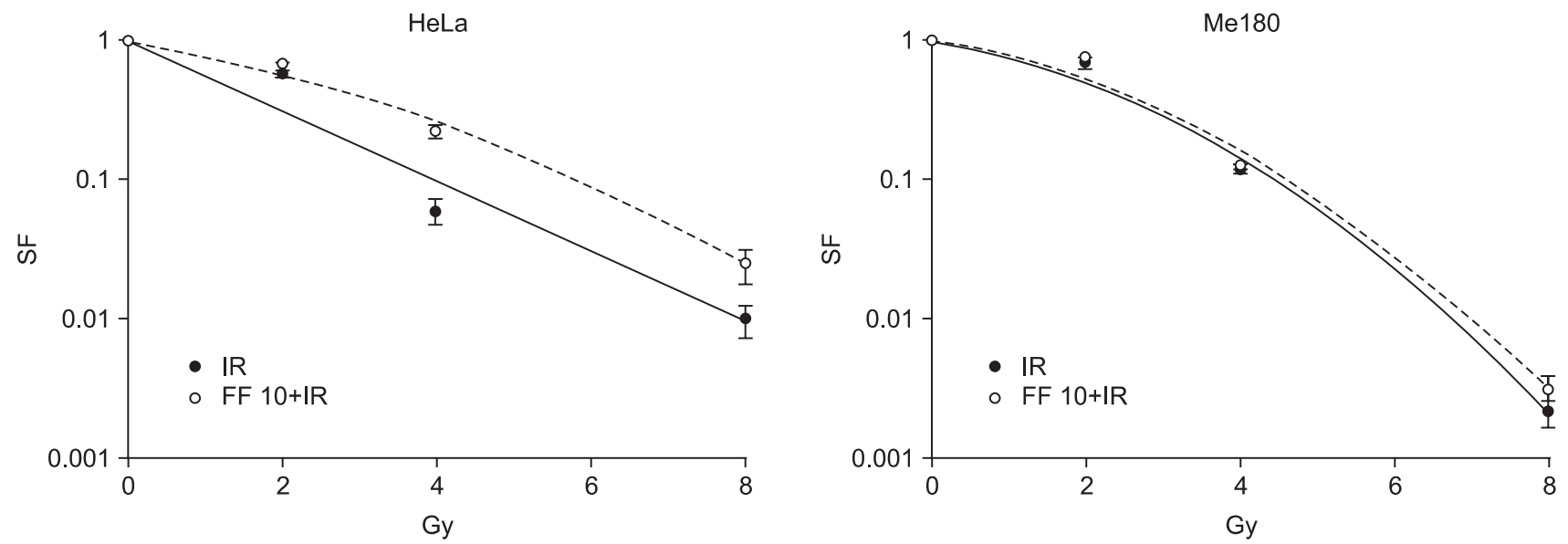

Fig. 4. The change of radiation sensitivity in fenofibrate (FF) pretreated HeLa and Me180 cells. Cells were treated with $10 \mu \mathrm{M} F \mathrm{FF}$ (FF10) for 48 hours and irradiated with 0-8 Gy X-rays. Following irradiation, cells were incubated at $37^{\circ} \mathrm{C} / 5 \% \mathrm{CO}_{2}$ for $6-7$ days and then colonies containing $\geq 50$ cells were scored. SF, surviving fraction; IR, ionizing radiation.

PCR was done. PPAR $\gamma$ mRNA was increased with increasing doses of FF in both cell lines. However, PPAR $\alpha$ mRNA was increased with increasing doses of FF in only HeLa cells (Fig. 3). This suggests increased protein expression of SOD1 and SOD2 by FF are related with PPAR $\alpha$ mRNA expression.

5. FF decreases radiation-induced cell death of HeLa cells Next, we were interested in whether FF affects on radiation sensitivity. Cells were treated with $10 \mu \mathrm{M}$ of FF for 48 hours and irradiated. The survival curves showed radioprotective effect of FF in HeLa cells. However, such an effect was not observed in Me180 cells (Fig. 4).

\section{Intrinsic ROS and ROS produced by irradiation are effectively scavenged in the FF-pretreated HeLa cells}

Finally, we were interested in whether FF modifies radiation sensitivity by scavenging ROS. To investigate whether SOD induced by FF contributes to scavenge ROS, HeLa cells were 


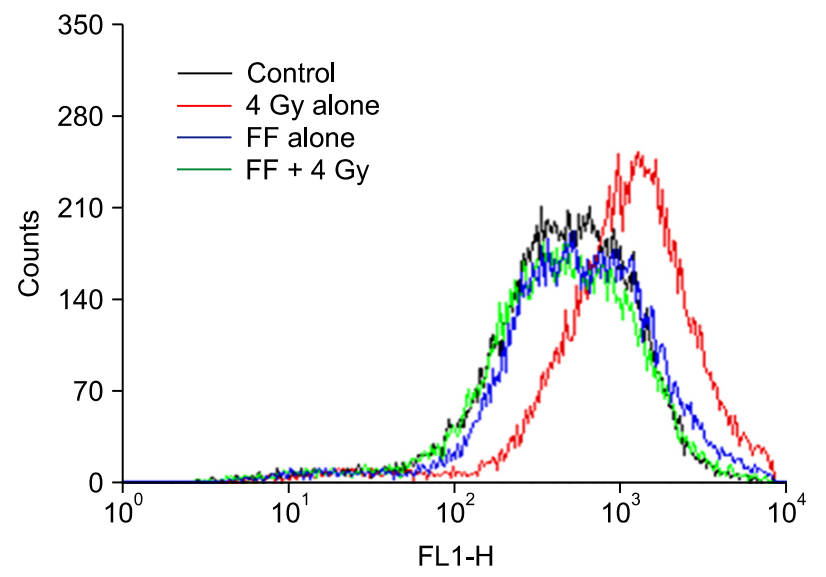

Fig. 5. reactive oxygen species (ROS) changes by fenofibrate (FF) treatment. HeLa cells were treated with $10 \mu \mathrm{M}$ of FF for 48 hours and irradiated with $4 \mathrm{~Gy}$. ROS produced by $4 \mathrm{~Gy}$ was decreased in the cells treated with FF.

treated with $10 \mu \mathrm{M}$ of FF for 48 hours and irradiated with 4 Gy. ROS produced by 4 Gy was decreased in the cells treated with FF (Fig. 5).

\section{Discussion and Conclusion}

Peroxisomes are found in virtually all eukaryotic cells. A major function of the peroxisome is the breakdown of fatty acid molecules, in a process called $\beta$-oxidation. Peroxisomes contain oxidative enzymes for certain oxidative reactions, like the $\beta$-oxidation of fatty acids. The $\beta$-oxidation of fatty acids are the main processes that generate ROS in peroxisomes, in particular $\mathrm{H}_{2} \mathrm{O}_{2}$. In several animal species, activators of PPAR $\alpha$, like fibrates increase the number and volume of peroxisomes and this peroxisomal proliferation increases the expression of peroxisomal oxidases that produce $\mathrm{H}_{2} \mathrm{O}_{21}$ such as acyl-CoA oxidase (ACO) [22]. Together with increased levels of $\mathrm{H}_{2} \mathrm{O}_{2}$ generation by peroxisomal enzymes, the reduced activities of antioxidant enzymes, such as catalase, SOD, and glutathione peroxidase (GPX) could induce oxidative stress in liver of rats treated with peroxisome proliferators $[23,24]$. However, peroxisomes or other cell compartments can also respond to oxidative stress and ROS. Among the enzymes in peroxisomes that degrade ROS, catalase and GPx decompose $\mathrm{H}_{2} \mathrm{O}_{2}$ produced by several peroxisomal oxidases and superoxide anions generated by peroxisomal xanthine oxidase are scavenged by MnSOD and CUZnSOD [22]. The PPRE, the binding site for PPAR, has been recently identified in the promoter area for the catalase and SOD genes, and therefore,

\section{Fenofibrate decreases radiation sensitivity via SOD induction}

catalase and SOD have been identified as the target enzymes of PPAR $\alpha[25,26]$. Previous studies have demonstrated that peroxisome proliferators like fibrates led to increases in the activity of peroxisomal oxidases, with a concomitant increase in antioxidant enzymes, in mainly catalase [10-16]. Among the synthetic peroxisome proliferators, the largest group consists of the amphipathic carboxylates, such as Wy-14643, benzafibrate, ciprofibrate, fenofibrate, and clofibric acid. These compounds have been shown to decrease hepatic lipid peroxidation or fibrosis in rats and mice liver by upregulating the expression of antioxidant enzymes, such as catalase, SOD, or ubiquinols [13-16]. In addition to fibrates, oxidative stress generated by UV irradiation or $\mathrm{H}_{2} \mathrm{O}_{2}$ has been shown to induce peroxisomal proliferation in human hepatoblastoma cell line [27]. Also, in purified peroxisomes from rat liver, the increased activity of SOD and GPx has been reported after induction of oxidative stress by endotoxin treatment [28]. A PPAR $\alpha$ ligand, Wy-14643, was also recently found to protect hippocampal neurons from oxidative damage induced by Abeta peptide and was reported that these events are mediated by the increase in the number of peroxisomes and in catalase activity [11]. Taken together, these studies suggest that the peroxisomes proliferation and the activation of ROS-producing oxidative enzymes in peroxisomes by fibrates might induce the activation of antioxidant enzymes responding to such oxidative stress in peroxisomes or other cell compartments. In this study, we also observed that the maximum SOD activity was about two times higher in FF-treated HeLa cells as compared to control, with a little bit increased catalase activity up to $10 \mu \mathrm{M}$ dose. This increased SOD activity was also correlated with increases in the expression of SOD proteins with increasing doses of FF. We have also confirmed, by using the quantitative RT-PCR method, that these increased expressions of SOD protein are caused from their mRNA transcriptions. In a previous study, the selective increase of the CuZnSOD activity in purified rat liver peroxisomes, as compared with mitochondria and cytosol has been reported after treatment with ciprofibrate, peroxisome proliferators [12].

More importantly, the increased activities of antioxidants, including the SODs, in cancer cells and tissues might reduce the cytotoxic effects of ROS-generating chemotherapy drugs and radiation, although the final effect may also depend on several factors, such as cell type, environmental factors, and the balance of antioxidant enzymes in the cell. However, the published studies about the relation of SODs to radiation sensitivity show some conflicting results depending on the 
increased levels of SOD activities. In the MnSOD-transfected HeLa cervical carcinoma cells, MnSOD overexpression protected the cells from growth suppression by serum deprivation, which is associated with increase in ROS generation [29]. In nonmalignant Chinese hamster ovary ( $\mathrm{CHO}$ ) cells, MnSOD expressing clone, which is with about 4-fold higher enzyme activity than its parental cells, was more resistant to irradiation than CuZnSOD and GPx expressing clones [30]. By contrast, MnSOD-transfected A172R human glioma cells with more than 5-fold increased activity of MnSOD and high SOD E. coli clone with more than a 10-fold increase in SOD activity became more sensitive to radiation [31,32]. These studies suggest that the increased activity of SOD may cause increased resistance to radiation and ROS, but the high SOD activity of more than 5 -fold compared with parental cells may lead to increased sensitivity in conditions without changes in other antioxidant enzymes, such as catalase and GPx, due to overproduction of toxic $\mathrm{H}_{2} \mathrm{O}_{2}$ or ${ }^{\bullet} \mathrm{OH}$ by SOD. Although oxidative stress can be quantified indirectly by measuring the products of oxidative damage, such as lipid peroxides and DNA adducts, the dichlorofluorescein (DCF) assay is a more direct and sensitive method to measure oxidative stress. In our results, the modest increased SOD activity of less than 2-fold by FF treatment contributed to decrease the level of 2,7-dichlorodihydrofluorescein (DCFH) oxidation, through scavenging intrinsic ROS in HeLa cells and ROS produced by $4 \mathrm{~Gy}$ irradiation. Therefore, this increase of ROS scavenging in FF pretreatment group resulted in the decrease of radiation sensitivity in clonogenic assay.

There is an intense argument on the concurrent use of antioxidants with chemotherapy and/or radiotherapy. Although considerable existing data support that dietary antioxidants do not interfere with these therapeutic modalities for cancer [33], many oncologists take the position that antioxidants by their nature undermine the free radical mechanism of chemotherapy and radiotherapy and should therefore generally be avoided during treatment. In conclusion, our study demonstrated that the increased SOD activity by FF, which is currently used in therapy of hyperlipidemia, decreases the radiation sensitivity in HeLa cells. Based on our findings, we speculate that the cytotoxic effect of radiation might be reduced in the patients taking the fibrates during radiotherapy. Therefore, some caution could be needed to clinicians and patients in this condition. Additional in vivo studies on radiation sensitivity modification by FF and clinical evaluations for radiotherapy response in the patients taking the fibrates during radiotherapy are needed in the future to reconfirm our findings.

\section{Conflicts of Interest}

No potential conflict of interest relevant to this article was reported.

\section{Acknowledgments}

This work was supported by the Korea Research Foundation Grant funded by the Korean Government (MOEHRD, Basic Research Promotion Fund; KRF-2007-313-E00370).

\section{References}

1. Balfour JA, McTavish D, Heel RC. Fenofibrate: a review of its pharmacodynamic and pharmacokinetic properties and therapeutic use in dyslipidaemia. Drugs 1990;40:260-90.

2. Grundy SM, Vega GL. Fibric acids: effects on lipids and lipoprotein metabolism. Am J Med 1987;83:9-20.

3. Sirtori CR, Franceschini G. Effects of fibrates on serum lipids and atherosclerosis. Pharmacol Ther 1988;37:167-91.

4. Todd PA, Gemfibrozil WA. A review of its pharmacodynamic and pharmacokinetic properties, and therapeutic use in dyslipidaemia. Drugs 1988;36:314-39.

5. Berger J, Moller DE. The mechanisms of action of PPARs. Annu Rev Med 2002;53:409-35.

6. Issemann I, Green S. Activation of a member of the steroid hormone receptor superfamily by peroxisome proliferators. Nature 1990;347:645-50.

7. Willson TM, Brown PJ, Sternbach DD, Henke BR. The PPARs: from orphan receptors to drug discovery. J Med Chem 2000;43:527-50.

8. Schoonjans $K$, Watanabe $M$, Suzuki $H$, et al. Induction of the acyl-coenzyme A synthetase gene by fibrates and fatty acids is mediated by a peroxisome proliferator response element in the C promoter. J Biol Chem 1995;270:19269-76.

9. Braissant O, Foufelle F, Scotto C, Dauça M, Wahli W. Differential expression of peroxisome proliferator-activated receptors (PPARs): tissue distribution of PPAR-alpha, -beta, and -gamma in the adult rat. Endocrinology 1996;137:354-66.

10. Reddy JK, Goel SK, Nemali MR, et al. Transcription regulation of peroxisomal fatty acyl-CoA oxidase and enoyl-CoA hydratase/3-hydroxyacyl-CoA dehydrogenase in rat liver by peroxisome proliferators. Proc Natl Acad Sci U S A 1986;83:1747-51.

11. Santos MJ, Quintanilla RA, Toro A, et al. Peroxisomal 
proliferation protects from beta-amyloid neurodegeneration. J Biol Chem 2005;280:41057-68.

12. Dhaunsi GS, Gulati S, Singh AK, Orak JK, Asayama K, Singh I. Demonstration of $\mathrm{Cu}-\mathrm{Zn}$ superoxide dismutase in rat liver peroxisomes. Biochemical and immunochemical evidence. J Biol Chem 1992;267:6870-3.

13. Inoue I, Noji S, Awata $T$, et al. Bezafibrate has an antioxidant effect: peroxisome proliferator-activated receptor alpha is associated with $\mathrm{Cu} 2+, \mathrm{Zn} 2+-$ superoxide dismutase in the liver. Life Sci 1998;63:135-44.

14. Toyama $T$, Nakamura $H$, Harano $Y$, et al. PPARalpha ligands activate antioxidant enzymes and suppress hepatic fibrosis in rats. Biochem Biophys Res Commun 2004;324:697-704.

15. Harano Y, Yasui K, Toyama T, et al. Fenofibrate, a peroxisome proliferator-activated receptor alpha agonist, reduces hepatic steatosis and lipid peroxidation in fatty liver Shionogi mice with hereditary fatty liver. Liver Int 2006;26:613-20.

16. Lores Arnaiz S, Travacio M, Monserrat AJ, Cutrin JC, Llesuy S, Boveris $A$. Chemiluminescence and antioxidant levels during peroxisome proliferation by fenofibrate. Biochim Biophys Acta 1997;1360:222-8.

17. Ramanan S, Kooshki M, Zhao W, Hsu FC, Robbins ME. PPARalpha ligands inhibit radiation-induced microglial inflammatory responses by negatively regulating NF-kappaB and AP-1 pathways. Free Radic Biol Med 2008;45:1695-704.

18. Gate L, Paul J, Ba GN, Tew KD, Tapiero H. Oxidative stress induced in pathologies: the role of antioxidants. Biomed Pharmacother 1999;53:169-80.

19. Bradford MM. A rapid and sensitive method for the quantitation of microgram quantities of protein utilizing the principle of protein-dye binding. Anal Biochem 1976;72:248-54.

20. Aebi H. Catalase in vitro. Methods Enzymol 1984;105:121-6.

21. Wan XS, Zhou Z, Ware JH, Kennedy AR. Standardization of a fluorometric assay for measuring oxidative stress in irradiated cells. Radiat Res 2005;163:232-40.

22. Schrader M, Fahimi HD. Peroxisomes and oxidative stress. Biochim Biophys Acta 2006;1763:1755-66.

23. Fahimi HD, Reinicke $A$, Sujatta $M$, et al. The short- and long- term effects of bezafibrate in the rat. Ann N Y Acad Sci 1982;386:111-35.

24. Goel SK, Lalwani ND, Reddy JK. Peroxisome proliferation and lipid peroxidation in rat liver. Cancer Res 1986;46:1324-30.

25. Yoo HY, Chang MS, Rho HM. Induction of the rat $\mathrm{Cu} /$ Zn superoxide dismutase gene through the peroxisome proliferator-responsive element by arachidonic acid. Gene 1999;234:87-91.

26. Girnun GD, Domann FE, Moore SA, Robbins ME. Identification of a functional peroxisome proliferator-activated receptor response element in the rat catalase promoter. Mol Endocrinol 2002;16:2793-801.

27. Schrader M, Wodopia R, Fahimi HD. Induction of tubular peroxisomes by UV irradiation and reactive oxygen species in HepG2 cells. J Histochem Cytochem 1999;47:1141-8.

28. Dhaunsi GS, Singh I, Hanevold CD. Peroxisomal participation in the cellular response to the oxidative stress of endotoxin. Mol Cell Biochem 1993;126:25-35.

29. Palazzotti B, Pani G, Colavitti R, et al. Increased growth capacity of cervical-carcinoma cells over-expressing manganous superoxide dismutase. Int J Cancer 1999;82:14550.

30. Sun J, Chen Y, Li M, Ge Z. Role of antioxidant enzymes on ionizing radiation resistance. Free Radic Biol Med 1998;24:586-93.

31. Zhong W, Oberley LW, Oberley TD, Yan T, Domann FE, St Clair DK. Inhibition of cell growth and sensitization to oxidative damage by overexpression of manganese superoxide dismutase in rat glioma cells. Cell Growth Differ 1996;7:117586.

32. Scott MD, Meshnick SR, Eaton JW. Superoxide dismutase amplifies organismal sensitivity to ionizing radiation. J Biol Chem 1989;264:2498-501.

33. Simone CB 2nd, Simone NL, Simone V, Simone CB. Antioxidants and other nutrients do not interfere with chemotherapy or radiation therapy and can increase kill and increase survival, Part 2. Altern Ther Health Med 2007;13:40-7. 